\title{
Event-Specific Body Characteristics of Elite Alpine Skiers in Relation to International Rankings
}

\section{Benjamin Vermeulen'1, Ron Clijsen ${ }^{1,2}$, Raphael Fässler ${ }^{2}$, Jan Taeymans ${ }^{1,3}$, Eva D’Hondt' Dirk Aerenhouts ${ }^{1}$}

\author{
${ }^{1}$ Department of Movement and Sports Sciences, Vrije Universiteit Brussel, Brussels, Belgium \\ ${ }^{2}$ University College Physiotherapy Thim van der Laan, Landquart, Switzerland \\ ${ }^{3}$ Bern University of Applied Sciences-Health, Bern, Switzerland \\ Email: benjamin.vermeulen@vub.be
}

How to cite this paper: Vermeulen, B., Clijsen, R., Fässler, R., Taeymans, J., D’Hondt, E., \& Aerenhouts, D. (2017). Event-Specific Body Characteristics of Elite Alpine Skiers in Relation to International Rankings. $A d$ vances in Anthropology, 7, 94-106. https://doi.org/10.4236/aa.2017.72007

Received: March 23, 2017

Accepted: May 7, 2017

Published: May 10, 2017

Copyright $\odot 2017$ by authors and Scientific Research Publishing Inc. This work is licensed under the Creative Commons Attribution International License (CC BY 4.0).

http://creativecommons.org/licenses/by/4.0/

\begin{abstract}
Objective: This explorative study examined potential performance indicators through a correlational analysis between morphological measures and international ranking within each alpine ski event for each gender separately. Methods: A cross-sectional sample of 58 elite alpine skiers were allocated into a technical or speed event group based on their international ski rankings. Several two-way $(2 * 2)(M)$ ANOVA's were used to examine the effect of gender and event group on age, BMI, sum of 6 skinfolds and somatotype. Forward stepwise discriminant analysis selected the most discriminating somatotype component between gender and/or event. Bivariate Pearson correlations between registered variables and international rankings per alpine ski event were examined for each gender separately. Results: Female speed specialists possessed more relative fat mass $(P=0.022)$ than female technical specialists. Irrespective of gender, technical specialists were lighter $(P<0.001)$ and had less relative fat mass than speed specialists $(P=0.008)$. Pearson values indicated moderate associations between speed rankings and body weight. High female speed rankings were associated with higher relative fat mass. High male speed rankings were associated with lower ectomorphy. Conclusion: Additional body weight appears to be beneficial in SPEED events. Fat mass correlated positively with higher rankings of female SPEED specialists. This observation should be monitored in female alpine skiers so that performance thresholds of relative body fat can be determined.
\end{abstract}

\section{Keywords}

Somatotype, Body Composition, Downhill, Slalom, Performance 


\section{Introduction}

Body profile affects performance in various sports and can be quantified using anthropometric indicators such as somatotype and body composition. Therefore, anthropometry has been widely used in previous research to clarify variations in body profiles between numerous sports (Reilly, Secher, Snell, \& Williams, 1990; Wilber \& Pitsiladis, 2012). Also within the same sport, individual anthropometric characteristics are related to athletes' performance levels and, therefore, help to distinguish potential elite from mediocre athletes (Bale, Bradbury, \& Colley, 1986). This makes the evaluation of anthropometry in elite athletic populations very interesting in order to describe desirable body profiles. In elite alpine skiing, field studies produce helpful data in order to determine biomechanical performance indicators. However, these studies are often difficult to perform because the measuring equipment is expensive and race conditions are difficult to replicate in study protocols (Gilgien, Spörri, Chardonnens, Kröll, \& Erich, 2013; Supej, 2010). In contrast, anthropometric characteristics, including somatotype and relative fat mass, can be relatively easily acquired and are used to study sub-disciplines, gender and/or performance level differences. Descriptive statistical analyses of elite alpine skiers' anthropometric characteristics should therefore be encouraged to find possible morphological indicators for competitive success (Carter \& Heath, 1990).

Alpine skiing consists of five events (i.e., Slalom [SL], Giant-Slalom [GS], Super-Giant Slalom [SGS], Downhill [DH] and Combined Events [COMB]) with very specific race setups, each requiring different biomechanical skills (Ropret, 2015). SL and GS skiers need to adapt to fast turning frequencies and absorb quick changes in ground reaction force. Hence, these events are often categorized as the most technical ones (TECH). On the other hand, SGS and DH skiers need to retain strong postures during the whole race to absorb high ground reaction forces generated by high velocities while turning or during hard landings. Therefore, SGS and DH are often referred to as the SPEED events (Gilgien, Crivelli, Spörri, Kröll, \& Müller, 2015; Nakazato, Scheiber, \& Müller, 2011; Vaverka, Vodickova, \& Elfmark, 2012). The combined event specialists (COMB) perform one $\mathrm{DH}$ race and two SL races in order to attain their international ranking. All of these ski events elicit a continuum, wherein TECH events (i.e., SL and GS) can be characterized by a high dynamic load and moderate velocity while SPEED events (i.e., GS and DH) may be characterized by a moderate dynamic load and high velocity. These variations in biomechanical and technical characteristics between TECH and SPEED ski events may present different physiological requirements and may also require different body profiles.

In the general elite alpine ski population, physiological studies show that aerobic capacity seems to be less important than high isometric and eccentric strength exerted by the lower extremities (Neumayr, Koller, \& Eibl, 2003; White \& Johnson, 1991). These physiological and biomechanical characteristics suggest the advantage of muscular bodies in alpine ski races which was already described by Chovanová (1979). She found that an average elite alpine skiers' somatotype 
was ecto-mesomorph (2.16-5.63-2.64). Orvanová (1987) found gender-specific body types, with female elite alpine skiers showing higher mean endomorphic components than male elite alpine skiers. Nonetheless, previous physiological research fell short to verify variations between alpine ski event specialists despite the sport's varying mechanical features, unless body composition and somatotype were examined. TECH specialists (i.e., SL and GS) typically had longer extremities and were slenderer than SPEED specialists (i.e., SGS and DH) as shown by a more pronounced ecto-mesomorph somatotype (2.00-5.53-2.89). SPEED specialists were found to be more robust showing a balanced mesomorph somatotype (2.32-5.72-2.39) with a lower centre of mass compared to TECH specialists (Chovanová, 1979). Accordingly, the assessment of alpine skiers' somatotype seems essential to bring nuances in body profiles and understand how it may affect performance in different alpine ski events (Aerenhouts, Clijsen, Fässler, Clarys, \& Baeyens, 2010; Song, 1982; Turnbull, Kilding, \& Keogh, 2009).

Previous results also presented an overall rising trend in body weight among elite alpine skiers (Neumayr et al., 2003; Osgnach et al., 2005; White \& Johnson, 1991). Neumayr et al. (2003) hypothesized this trend to be the result of an increase in upper body resistance training as alpine skiers benefit from additional weight to gain more momentum (Hébert-Losier, Supej, \& Holmberg, 2014). Osgnach et al. (2005) confirmed this positive trend in body weight over time because of an increased lean body mass found in male Italian World Cup alpine skiers, although they could not specify whether or not this resulted from upper body resistance training. Additional findings indicated that male Austrian World Cup skiers also appeared to be heavier and had more relative body fat compared to their lower ranked Italian World Cup competitors (Osgnach et al., 2005). In contrast, Scherr et al. (2011) examined elite alpine skiers' tissue ratios over time and found that more fat free mass was associated with better rankings. This raises a question concerning fat mass; to what extent can its presence be beneficial for an elite alpine skier? Additional research could determine the relevance of somatotype and body composition and how they vary between alpine eventspecialists. Furthermore, these outcome variables may function as indicators to develop adequate talent identification, training and nutritional strategies for young and adult elite alpine skiers.

This cross-sectional research revolves around two research questions: 1) do certain anthropometric characteristics (including somatotype and relative fat mass) differ between male and female elite alpine skiers categorized in TECH or SPEED event groups, and 2) do any of these anthropometric measures (including somatotype and relative fat mass) correlate with male or female elite alpine skiers' ranking within each ski event (i.e., SL, GS, SGS, DH).

\section{Methods}

\subsection{Participants and Allocation}

Fifty-eight young adult elite alpine skiers $(\mathrm{n} \hat{o}=34 \& \mathrm{n}$ 우 $=24)$ from different ski federations volunteered to be evaluated on their anthropometry during 
pre-season test sessions in 2009 by trained examiners following the ISAK guidelines (Marfell-Jones, Olds, Stewart, \& Carter, 2006). Federation International de Ski (FIS) points from the most recent FIS-point list represented their quantitative ranking on international competitions for each alpine ski event (i.e., SL, GS, SGS, DH) during that particular period (FIS, 2009).

In order to answer the first research question, skiers were allocated to the TECH group if their FIS-ranking for SL was higher than their DH ranking. Likewise, if their FIS ranking for DH was higher than their SL ranking, skiers were allocated to the SPEED category. This categorisation is corroborated due to the biomechanical continuum between SL and DH events (Gilgien et al., 2015). Groups for the second research question were based upon each ski event (i.e., SL, GS, SGS, DH) because each skier had rankings across all ski events but typically had higher rankings for the events in which they were specialized.

\subsection{Measurements and Calculations}

Apart from age, gender and nationality, several anthropometric variables were collected. Body height was measured to the nearest $0.1 \mathrm{~cm}$ with a Martin anthropometer. Body weight was determined using a TANITA-TBF 611 scale, accurate up to 200 grams. Accordingly, weight $\cdot h e i g h t^{2}-1\left(\mathrm{~kg} \cdot \mathrm{m}^{2}-1\right)$ quantified participants' Body Mass Index (BMI). Upper arm and calf circumference were measured to the nearest $0.1 \mathrm{~cm}$ using a Rosscraft measuring tape. In addition, 6 skinfolds (i.e., triceps, biceps, subscapular, supraspinale, abdomen and medialcalf site) were measured using a Harpenden calliper with an accuracy up to 0.1 $\mathrm{cm}$. Based on these measurements, corrected girths were calculated by subtracting skinfolds from their designated limb circumferences. Bi-epicondylar humerus and femur breadths were measured using a Rosscraft bone calliper, accurate up to $0.1 \mathrm{~cm}$. A sum of the 6 skinfolds (SF) was calculated and corrected for body height.

Somatotype components (i.e., endomorphy, mesomorphy and ectomorphy) were calculated using the Carter (2002) method operationalized by sweat technologies' Somatotype software (v1.2.6). Somatotype attitudinal mean (SAM) and somatotype attitudinal distance (SAD) were not calculated to compare group means because these two constructs were disapproved by Cressie, Withers, \& Craig (1986) to find differences between sub-groups. They observed a loss of statistical nuances due to the premature collapse of the three somatotype vectors into a scalar value without the appropriate degrees of freedom for the F-ratio.

\subsection{Statistical Analyses}

IBM SPSS 24.0 software was used for statistical analyses. Kolmogorov-Smirnov tests assessed statistical normality of all variables. A $2 * 2$ ANOVA procedure tested differences in demographical data (i.e. age) while a $2 * 2$ MANOVA tested differences in anthropometric characteristics (i.e., body height, body weight, BMI and sum of SF corrected for body height) according to gender (male vs female) and ski event groups (TECH vs SPEED). Cressie et al. (1986) proposed a 
new statistical method to analyse somatotype data using a MANOVA. By using this method, the intercorrelation between the individual somatotype components can be accounted for. If this analysis is significant $(P<0.05)$, the MANOVA was followed by a forward stepwise discriminant analysis. This solution got support from the original developers of both SAM and SAD in their most recent instruction manual about somatotype (Carter, 2002). Accordingly, the second $2 * 2$ MANOVA procedure tested differences in somatotype profiles according to gender (male vs. female) and event groups (TECH vs. SPEED). When an interaction effect was present, the data file was split by gender. The forward stepwise discriminant analysis could thereby indicate gender specific somatotype components and their individual classification power between SPEED and TECH event categorisation. This is only possible if the discriminant function of a pairwise comparison is significant $(P<0.05)$. When no interaction effect was present and main effects were significant, two forward stepwise discriminant analyses were performed to find distinctive somatotype components between (1) gender and (2) event groups when the discriminant functions of these two comparisons were significant.

Bivariate Pearson correlations were inspected between FIS-points of all ski events (i.e., SL, GS, SGS, DH) and athletes' age, somatotype, body height, body weight, BMI and sum of SF for males and females separately. FIS-points are international ski rankings so that lower points indicate a better ranking. Therefore, negative Pearson $r$-values indicate a positive association between higher anthropometric values and a better ranking. The strength of an association was categorized using the guidelines of Evans (1995) and were significant if $P<0.05$.

\section{Results}

\subsection{Participant Characteristics}

All data were normally distributed. For the TECH skiers, SL FIS-rankings ranged from 1.83 to 80.75 ( $24.7 \pm 17.6)$ and GS FIS-rankings ranged from 2.79 to 49.27 $(19.2 \pm 11.1)$. For the SPEED skiers, SGS FIS-rankings ranged from 0.00 to 89.79 $(27.3 \pm 21.4)$ and DH FIS-rankings ranged from 0.00 to $95.56(29.4 \pm 23.4)$. Univariate analysis of demographic data resulted in an interaction effect in age between gender ${ }^{*}$ event groups (Fgender $*$ event $=7.001 ; \mathrm{p}=0.001$ ), with female SPEED specialists $(25.5 \pm 3.89)$ being significantly older than female TECH specialists $(20.2 \pm 3.11)$. There was no significant difference in age between male SPEED and male TECH specialists.

\subsection{Anthropometric Characteristics}

There were no interaction effects in anthropometric data between male and female TECH or SPEED specialists although it approached significance. Irrespective of ski events, male and female skiers differed in anthropometric data. Further univariate analysis showed that male skiers have a higher average body height, body weight and BMI, but a lower sum of SF than female skiers. Irrespective of gender, skiers specialized in TECH events differed in anthropometric 
data in comparison with SPEED specialists. Further univariate analysis showed that SPEED specialists had a higher body weight, BMI and sum of SF corrected for body height than TECH specialists (Table 1).

Somatotype analysis by MANOVA (Table 1) between male and female skiers specialized in either SPEED or TECH events showed to have interaction effects (gender * event). Univariate analyses show no significant differences in separate somatotype components although mesomorphy approached significance. Male skiers showed to have different somatotype profiles in comparison to female skiers (between gender). Male skiers were more mesomorphic and less endomorphic than female skiers. Irrespective of gender, TECH skiers showed lower endomorphic components and higher ectomorphic components than SPEED skiers (between event).

Forward stepwise discriminant analyses (see Table 2) could also not elicit discriminative somatotype components between TECH and SPEED specialists in each gender separately although the discriminant functions approached significance (gender * event). Irrespective of event, males and female alpine skiers were best classified using endomorphy followed by mesomorphy and ectomorphy (between gender). Irrespective of gender, TECH and SPEED skiers could not be classified by somatotype components.

There appear to be moderating interaction effects of gender * event in somatotype profiles but not in anthropometric data. Further explorative analyses

Table 1. Anthropometric differences according to gender and/or event groups.

\begin{tabular}{|c|c|c|c|c|c|c|c|c|}
\hline Effect & Comparison & $\mathrm{BH}(\mathrm{cm})$ & BW (kg) & $\mathrm{BMI}\left(\mathrm{kg} \cdot \mathrm{m}^{2}-1\right)$ & $\sum 6 \mathrm{SF}(\mathrm{mm})$ & Endo & Meso & Ecto \\
\hline \multirow[t]{4}{*}{ Gender $\times$ event } & 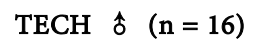 & $180.4 \pm 4.5$ & $82.1 \pm 5.1$ & $25.2 \pm 1.3$ & $53.2 \pm 13.0$ & $2.8 \pm 0.6$ & $5.6 \pm 0.9$ & $1.8 \pm 0.6$ \\
\hline & SPEED \& $(\mathrm{n}=18)$ & $180.8 \pm 5.0$ & $86.7 \pm 6.1$ & $26.9 \pm 1.5$ & $58.9 \pm 12.7$ & $3.1 \pm 0.6$ & $6.4 \pm 0.8$ & $1.4 \pm 0.6$ \\
\hline & $\mathrm{TECH}$ 우 $(\mathrm{n}=16)$ & $166.1 \pm 5.7$ & $64.1 \pm 4.1$ & $23.2 \pm 1.7$ & $69.5 \pm 11.2$ & $3.8 \pm 0.6$ & $4.8 \pm 1.2$ & $1.9 \pm 0.8$ \\
\hline & SPEED 우 $(\mathrm{n}=8)$ & $169.3 \pm 6.6$ & $70.8 \pm 6.3$ & $24.7 \pm 0.8$ & $83.3 \pm 16.0$ & $4.4 \pm 0.7$ & $4.7 \pm 0.6$ & $1.5 \pm 0.4$ \\
\hline Multivariate & $F$ (P-value) & \multicolumn{4}{|c|}{$2.303(0.071)$} & \multicolumn{3}{|c|}{$3.295(0.028)$} \\
\hline Univariate & $F$ (P-value) & $\begin{array}{c}0.911 \\
(0.344)\end{array}$ & $\begin{array}{c}0.498 \\
(0.483)\end{array}$ & $\begin{array}{c}0.045 \\
(0.833)\end{array}$ & $\begin{array}{c}0.654 \\
(0.422)\end{array}$ & $\begin{array}{c}0.368 \\
(0.546)\end{array}$ & $\begin{array}{c}3.209 \\
(0.079)\end{array}$ & $\begin{array}{c}0.001 \\
(0.975)\end{array}$ \\
\hline \multirow[t]{2}{*}{ Between gender } & Male $(\mathrm{n}=34)$ & $180.6 \pm 4.7$ & $84.5 \pm 6.0$ & $25.9 \pm 1.6$ & $56.2 \pm 13.0$ & $2.9 \pm 0.6$ & $6.0 \pm 0.9$ & $1.6 \pm 0.6$ \\
\hline & Female $(n=24)$ & $167.2 \pm 6.1$ & $66.3 \pm 5.9$ & $23.7 \pm 1.6$ & $74.1 \pm 14.3$ & $4.0 \pm 0.7$ & $4.8 \pm 1.0$ & $1.8 \pm 0.7$ \\
\hline Multivariate & $F$ (P-value) & \multicolumn{4}{|c|}{$65.601(<0.001)$} & \multicolumn{3}{|c|}{$27.991(<0.001)$} \\
\hline Univariate & $F$ (P-value $)$ & $\begin{array}{c}76.400 \\
(<0.001)\end{array}$ & $\begin{array}{l}130.147 \\
(<0.001)\end{array}$ & $\begin{array}{c}24.315 \\
(<0.001)\end{array}$ & $\begin{array}{c}32.845 \\
(<0.001)\end{array}$ & $\begin{array}{c}44.256 \\
(<0.001)\end{array}$ & $\begin{array}{c}23.496 \\
(<0.001)\end{array}$ & $\begin{array}{c}0.063 \\
(0.802)\end{array}$ \\
\hline \multirow[t]{2}{*}{ Between events } & $\mathrm{TECH}(\mathrm{n}=32)$ & $173.3 \pm 8.8$ & $73.1 \pm 10.2$ & $24.2 \pm 1.8$ & $61.3 \pm 14.6$ & $3.3 \pm 0.8$ & $5.2 \pm 1.1$ & $1.9 \pm 0.7$ \\
\hline & SPEED $(n=26)$ & $177.3 \pm 7.6$ & $81.8 \pm 9.6$ & $26.0 \pm 1.6$ & $66.4 \pm 11.2$ & $3.5 \pm 0.9$ & $5.9 \pm 1.1$ & $1.4 \pm 0.5$ \\
\hline Multivariate & $F$ (P-value) & \multicolumn{4}{|c|}{$4.926(\mathbf{0 . 0 0 2})$} & \multicolumn{3}{|c|}{$3.141(0.033)$} \\
\hline Univariate & $F$ (P-value) & $\begin{array}{c}1.494 \\
(0.227)\end{array}$ & $\begin{array}{c}14.654 \\
(<0.001)\end{array}$ & $\begin{array}{c}12.26 \\
(0.001)\end{array}$ & $\begin{array}{c}7.516 \\
(0.008)\end{array}$ & $\begin{array}{c}5.417 \\
(0.024)\end{array}$ & $\begin{array}{c}1.393 \\
(0.243)\end{array}$ & $\begin{array}{c}6.157 \\
(0.016)\end{array}$ \\
\hline
\end{tabular}

$\mathrm{BH}=$ Body Height, BW = Body Weight, BMI = Body Mass Index, SF = Skinfold corrected for body height, Endo = Endomorphy, Meso = Mesomorphy, Ecto $=$ Ectomorphy, $\mathrm{TECH}=$ Slalom and Giant slalom specialists, SPEED = Super Giant Slalom and Downhill specialists. 
Table 2. Further analyses of somatotype profiles disclosing discriminative somatotype components within a pairwise comparison.

\begin{tabular}{|c|c|c|c|c|c|c|c|c|c|c|c|c|}
\hline \multirow[t]{3}{*}{ Effects } & \multirow[t]{3}{*}{$\begin{array}{c}\text { Pairwise } \\
\text { comparison }\end{array}$} & \multicolumn{2}{|c|}{$\begin{array}{c}\text { Canonical } \\
\text { Discriminant Function }\end{array}$} & \multicolumn{9}{|c|}{$\begin{array}{c}\text { Forward stepwise } \\
\text { discriminant analysis }\end{array}$} \\
\hline & & \multirow{2}{*}{$\begin{array}{l}\text { Canonical } \\
\text { Correlation }\end{array}$} & \multirow[b]{2}{*}{ Chi-square $(P)$} & \multicolumn{3}{|c|}{ Step 1} & \multicolumn{3}{|c|}{ Step 2} & \multicolumn{3}{|c|}{ Step 3} \\
\hline & & & & SC & $F$ to enter & $P$ & SC & $\mathrm{F}$ to enter & $P$ & SC & $F$ to enter & $P$ \\
\hline \multirow{2}{*}{$\begin{array}{c}\text { Gender X } \\
\text { event }\end{array}$} & $\begin{array}{c}\text { TECH ( } \hat{\jmath} \text { ) vs. } \\
\text { SPEED ( } \hat{o} \text { ) }\end{array}$ & 0.455 & $7.071(0.070)$ & Meso & 6.757 & 0.014 & Endo & 0.997 & 0.032 & Ecto & 0.278 & 0.070 \\
\hline & $\begin{array}{l}\mathrm{TECH} \text { (우) vs. } \\
\text { SPEED (우) }\end{array}$ & 0.566 & $7.927(\mathbf{0 . 0 4 8})$ & Endo & 3.291 & 0.083 & Ecto & 0.921 & 0.147 & Meso & 4.536 & 0.048 \\
\hline $\begin{array}{l}\text { Between } \\
\text { gender }\end{array}$ & $\begin{array}{l}\text { Male vs. } \\
\text { Female }\end{array}$ & 0.755 & $45.958(<0.001)$ & Endo & 37.845 & $<0.001$ & Meso & 18.267 & $<0.001$ & Ecto & 2.215 & $<0.001$ \\
\hline $\begin{array}{l}\text { Between } \\
\text { events }\end{array}$ & $\begin{array}{l}\text { TECH vs. } \\
\text { SPEED }\end{array}$ & 0.349 & $7.062(0.070)$ & Ecto & 7.228 & 0.009 & Meso & 0.152 & 0.033 & Endo & 0.294 & 0.070 \\
\hline
\end{tabular}

$\mathrm{TECH}=$ Slalom and Giant Slalom specialists, SPEED = Super Giant Slalom and Downhill specialists, SC = somatotype component, Endo = endomorphy, Meso $=$ mesomorphy, Ecto $=$ ectomorphy; Step 1, 2 and 3 can only be interpreted when Canonical Discriminant Function is significant $(P<0.05)$. Forward stepwise discriminant analysis shows how well the somatotype components can categorize the skiers in the defined groups within a pairwise comparison. Step 1: Most important somatotype component which can allocate a skier into the right group within a pairwise comparison if $\mathrm{F}$ to enter is significant $(P<$ 0.05). Step 2: Second most important somatotype component which can allocate a skier into the right group within a pairwise comparison if $\mathrm{F}$ to enter is significant $(P<0.05)$. Step 3: Third most important somatotype component which can allocate a skier into the right group within a pairwise comparison if $\mathrm{F}$ to enter is significant $(P<0.05)$.

using independent samples t-test for each anthropometric measure in males and females separately may determine which anthropometric measure is influenced by these moderating effects. Male SPEED specialists weigh more $(\mathrm{t}=-2.389 ; P=$ $0.023)$ and have a higher BMI $(\mathrm{t}=-2.654 ; P=0.012)$ than male TECH specialists. Female SPEED specialists weigh more $(\mathrm{t}=-0.145 ; P=0.005)$, have a higher BMI $(\mathrm{t}=-2.360 ; P=0.028)$ and have more relative fat mass $(\mathrm{t}=-2.475 ; P=$ $0.022)$ than female TECH specialists. These findings elaborate the interaction effect in somatotype data (see Figure 1).

\subsection{Anthropometrics in Relation to International Ranking}

Since there was a significant difference between male and female skiers in demographic and anthropometric (including somatotype) data, bivariate Pearson correlations were examined when the data file was split by gender (see Table 3). In the male sample, demographic data indicated that older age was strongly associated with higher SGS rankings $(P=0.001)$ and moderately associated with high DH rankings $(P=0.042)$. Anthropometric data indicated that high body weight $(P=0.014)$ and high BMI $(P=0.035)$ were moderately associated with SGS rankings. High body weight $(P=0.004)$ was strongly associated with high DH rankings. Body Mass Index $(P=0.009)$ was moderately associated with high DH rankings. Somatotype data indicated that a low ectomorph component was moderately associated with high DH rankings $(P=0.045)$.

In the female sample, demographic data indicated that older age is strongly associated with high GS $(P=0.001)$, high SGS $(P=0.004)$ and high DH $(P=$ $0.001)$ rankings. Anthropometric data showed that a high body weight $(P=$ $0.036)$, BMI $(P=0.016)$ and sum of SF $(P=0.018)$ were moderately associated 

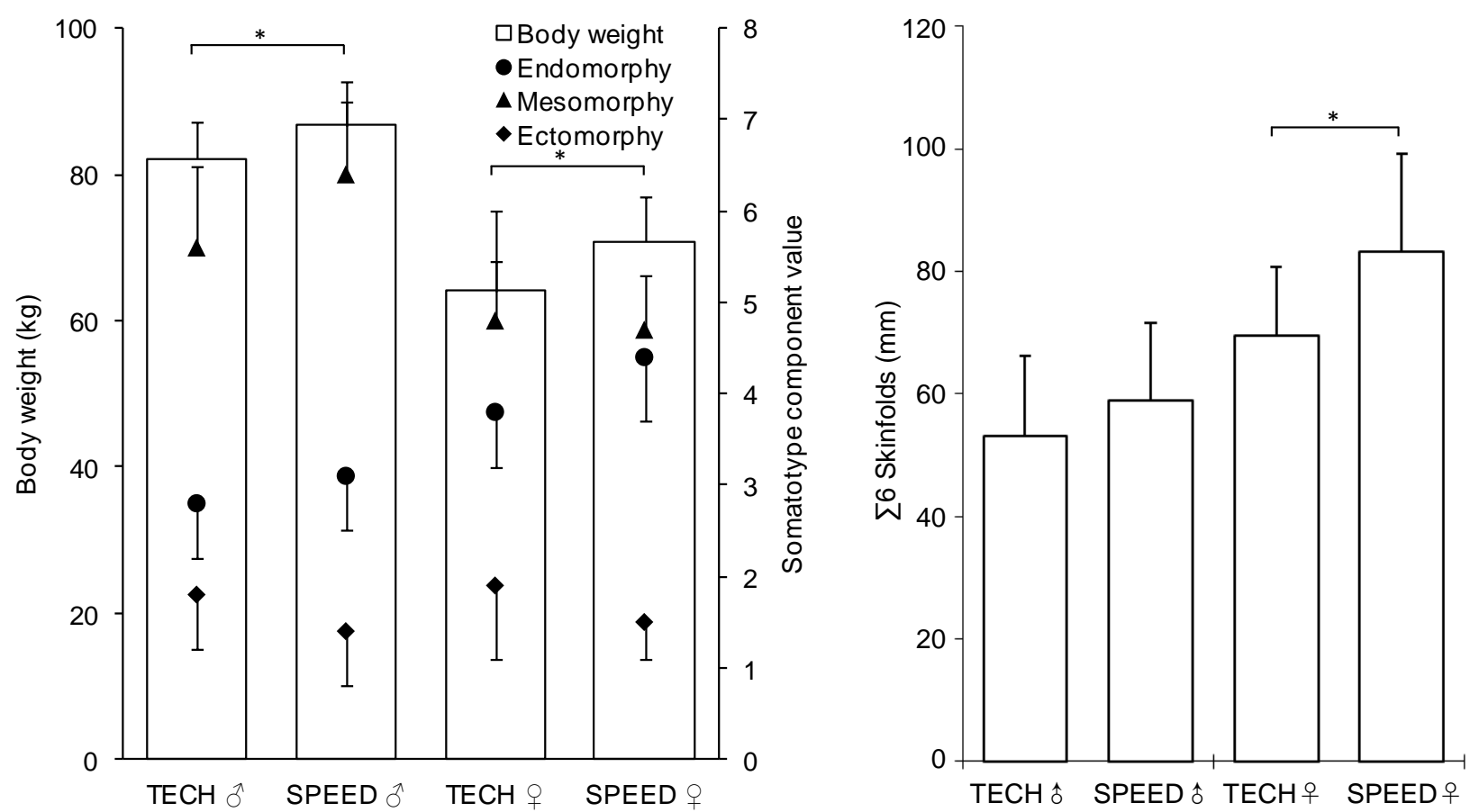

Figure 1. Somatotype components and body weight compared between TECH and SPEED specialists in males and females (panel A). Relative fat mass compared between TECH and SPEED specialists in males and females (panel B). $\left({ }^{*} P=0.05\right)$ Significant difference in body weight and $\Sigma 6$ Skinfolds between TECH and SPEED specialists using independent samples t-test within males and females separately. Somatotype profiles were also significantly different although no discriminative somatotype component could be found.

Table 3. Bivariate Pearson correlations between demographic/anthropometric/somatotype data and international rankings for each ski event (i.e., SL, GS, SGS, DH).

\begin{tabular}{|c|c|c|c|c|c|c|c|c|}
\hline & \multicolumn{4}{|c|}{ Male } & \multicolumn{4}{|c|}{ Female } \\
\hline & \multicolumn{2}{|c|}{ TECH } & \multicolumn{2}{|c|}{ SPEED } & \multicolumn{2}{|c|}{ TECH } & \multicolumn{2}{|c|}{ SPEED } \\
\hline & FISp SL & FISp GS & FISp SGS & FISp DH & FISp SL & FISp GS & FISp SGS & FISp DH \\
\hline & $\mathrm{n}=26$ & $\mathrm{n}=26$ & $\mathrm{n}=22$ & $\mathrm{n}=20$ & $\mathrm{n}=23$ & $\mathrm{n}=23$ & $\mathrm{n}=23$ & $\mathrm{n}=21$ \\
\hline \multicolumn{9}{|l|}{ Demographic data } \\
\hline Age & -0.195 & -0.323 & $-0.564^{\star *}$ & $-0.386^{\star}$ & 0.216 & $-0.642^{\star \star}$ & $-0.572^{\star \star}$ & $-0.641^{\star *}$ \\
\hline \multicolumn{9}{|l|}{ Anthropometric data } \\
\hline Body height $(\mathrm{cm})$ & -0.100 & 0.029 & -0.154 & -0.129 & -0.318 & -0.174 & -0.088 & -0.389 \\
\hline Body weight (kg) & -0.116 & 0.238 & $-0.445^{\star}$ & $-0.522^{* *}$ & -0.083 & -0.347 & $-0.429^{*}$ & $-0.563^{* *}$ \\
\hline $\mathrm{BMI}\left(\mathrm{kg} \cdot \mathrm{m}^{2}-1\right)$ & -0.041 & 0.246 & $-0.387^{\star}$ & $-0.482^{\star *}$ & 0.234 & -0.301 & $-0.484^{*}$ & -0.353 \\
\hline$\sum 6 \mathrm{SF}(\mathrm{mm})$ & 0.048 & 0.061 & -0.198 & -0.361 & -0.080 & -0.281 & $-0.477^{\star}$ & $-0.578^{* *}$ \\
\hline \multicolumn{9}{|l|}{ Somatotype data } \\
\hline Endomorphy & 0.095 & 0.094 & -0.283 & -0.329 & 0.232 & -0.194 & $-0.433^{\star}$ & $-0.452^{*}$ \\
\hline Mesomorphy & 0.045 & 0.211 & -0.230 & -0.287 & 0.062 & -0.134 & -0.089 & 0.307 \\
\hline Ectomorphy & -0.009 & -0.214 & 0.294 & $0.381^{*}$ & -0.359 & 0.150 & 0.399 & 0.117 \\
\hline
\end{tabular}

TECH $=$ SL and GS specialists, SPEED = SGS and DH specialists, FISp = International ski ranking, SL = Slalom, GS = Giant Slalom, SGS = Super Giant Slalom, DH = Downhill, SF $=$ Skinfold corrected for body height; ${ }^{\star}$ significant difference $(P<0.05),{ }^{\star}$ significant difference $(P<0.01)$, Negative Pearson correlation values show beneficial associations between high rankings and higher values in demographic, somatotype and anthropometric data; Positive Pearson correlation values show beneficial associations between high rankings and lower values in demographic, somatotype and anthropometric data. 
with high SGS rankings. A high body weight $(P=0.006)$ was strongly associated with high DH rankings. A high sum of $\mathrm{SF}(P=0.005)$ was strongly associated with high DH rankings. Somatotype data elicited that a high endomorph component was moderately associated with SGS $(P=0.034)$ and DH $(P=0.035)$ rankings.

\section{Discussion}

The present study examined whether male and female elite alpine skiers showed different body profiles when they are categorised into alpine ski event-groups (TECH vs SPEED) they were specialized in. Further bivariate Pearson correlation analyses determined which anthropometric characteristics were associated with high alpine ski rankings in four alpine ski events (i.e., SL, GS, SGS, DH) in each gender separately.

Demographic results indicated that female TECH (i.e., SL and GS) skiers were significantly younger than female SPEED (i.e., SGS and DH) skiers, although this difference in age was not found in the male elite alpine skiers. Irrespective of event specialisation, the anthropometric results elicited significant and known differences between male and female alpine skiers. Male skiers showed to be taller and heavier than female alpine skiers, although female elite alpine skiers showed higher relative fat mass than male alpine skiers. These results also concur with the results of Orvanová (1987) and White \& Johnson (1991). Irrespective of gender, SPEED specialists had a higher BMI than TECH specialists due to heavier bodies less ectomorph body profiles which concur with the results of Chovanová (1979). SPEED specialists were also found to have more relative fat mass than TECH specialists, which has never been demonstrated in previous literature.

In contrast to anthropometric results, somatotype results did show interaction effects although forward stepwise discriminant analysis could not determine which somatotype components were responsible for these effects. Nonetheless, these results approached significance and may be interpreted with caution. Male SPEED specialists may show to have a more musculoskeletal robust body and a higher overall fatness than male TECH specialists. Female SPEED specialists may show a higher overall fatness compared to female TECH specialists. These findings may indicate that male SPEED specialists attain additional body weight through additional lean body mass while female SPEED specialists attain additional body weight via additional fat mass.

This statement may be supported by our explorative analyses and correlational analyses in anthropometric data. In the explorative analyses, female SPEED specialist showed to have more relative fat mass than female TECH specialists although male specialists did not differ in relative mass. Additionally, our correlational analyses implied the importance of additional body weight in SPEED events. Furthermore, a higher endomorph value and a higher sum of SF in female skiers were moderately associated with higher female rankings in SPEED events which implies the advantage of additional body weight through 
additional fat mass in female SPEED events. Application of the Durnin \& Womersley (1974) regression formula elicited an average body fat percentage of $28.5 \%$ in the examined female alpine skiers which ranged between $18 \%$ and $37 \%$. These were similar results as found by Taeymans et al. (2010) and is well above the overall norm in elite female athletes $( \pm 18 \%)$ (Kenny, Wilmore, \& Costill, 2012). In male elite alpine skiers however, a high BMI was associated with high SPEED rankings although no association with sum of SF was found. When male SPEED somatotypes are taken into account, these results indicated that male SPEED specialists may acquire their additional body weight through additional muscle tissue. Moreover, non-linear, robust body profiles seem to be beneficial in male SPEED events because higher ectomorphy values show an inverse relationship with high male SPEED rankings.

It is well-known that a heavy body profile is beneficial in alpine skiing because it helps overcome frictional forces through a higher amount of potential energy (Gilgien et al., 2013; Supej, Kipp, \& Holmberg, 2011). This may explain why there is a positive secular trend in body weight among elite alpine skiers (Neumayr et al., 2003; Osgnach et al., 2005; White \& Johnson, 1991). However, higher mean velocities are acquired in SPEED events and the specialists in these events need to absorb higher ground reaction forces than specialists in TECH events (Gilgien, Spörri, Kröll, Crivelli, \& Müller, 2014). Subsequently, SPEED specialists may need heavier and more muscular body profiles than TECH specialists to attain higher mean velocities and distribute the generated forces across the entire body.

This study brings additional depth about how body weight influences performance in alpine skiing and how gender and event specialization moderate body weights. It is suggested that male elite SPEED specialists attain additional body weight through additional muscle mass, whereas female elite SPEED specialists may attain this through a combination of both fat and muscle mass. The observation concerning the benefit of additional fat mass in female skiers may be hazardous. Besides general health concerns, fat tissue increases body weight but has no contractile properties, and therefore may facilitate injury during alpine ski racing. Nonetheless, associations between body weight and international SPEED rankings are moderate which implies the presence of other influential factors not included in this study protocol.

A limitation to this study might be the small sample size and its cross-sectional design. Explorative analyses also showed that senior elite alpine skiers weighed more than junior elite alpine skiers in both gender types which may explain the strong correlations between age and international SPEED rankings in male and female skiers. Since the measurements were performed in 2009, other secular trends may be present in anthropometric characteristics of alpine skiers which are not documented. Nevertheless, very few publications on alpine skiers' body profiles have recently been published which could make these anthropometric examinations at this competitive level useful for alpine ski trainers.

Future research should specifically focus on somatotyping and tissue ratios 
since these parameters may explain some gradient of success in competitive alpine ski events when longitudinal designs are analysed. Somatotyping also appears to be more sensitive when moderation effects (gender/event specialisation) are present although adequate sample sizes are needed when individual somatotype components are necessary in subsequent examination. Fat mass and fat free mass, including muscle mass, can bring nuances in body profiles of young and adult alpine skiers so that maturation effects can be accounted for in younger alpine skiers. Finally, research can also focus on interdisciplinary collaborations so that psychological state, physiological state and numerous biomechanical variables are simultaneously considered to find indicators in competitive alpine ski success (Federolf, 2012; Hébert-Losier et al., 2014; May, Veach, Reed, \& Griffey, 1985).

\section{Conclusion}

Our findings bring about nuances in previous literature which states that heavy bodies are beneficial in alpine ski races. The inclusion of somatotype and its relation to international rankings implies moderation effects of event specialization and gender in competitive alpine skiing. Male elite alpine skiers specialized in TECH events are less heavy than males specialized in SPEED events which might be due to the lower musculoskeletal robustness in male TECH specialists. Female TECH specialists also show to be less heavy accompanied by less relative fat mass than female SPEED specialists, which may suggest that female SPEED specialists primarily have more body weight through additional fat mass. In both genders, additional fat tissue may be beneficial in SPEED events. However, relative body fatness should be monitored carefully in case it would exceed the wellestablished health limits or increase injury risk. Future studies could determine how much bodyfat in SPEED specialists may be acquired until it becomes hazardous.

\section{Acknowledgements}

We would like to thank all volunteers and the ski federations for their cooperation. Dr. Daan Hubert provided significant input in the statistical analysis. Dr. Sofie Vermeulen contributed in writing the manuscript.

\section{References}

Aerenhouts, D., Clijsen, R., Fässler, R., Clarys, P., \& Baeyens, J.-P. (2010). Somatotype and Kinanthropometric Characteristics of Male and Female Elite Technic and Speed Senior Alpine Skiers. In E. Müller, S. Lindinger, \& T. Stöggl (Eds.), 5th International Congress on Science and Skiing (pp. 51-58). Meyer \& Meyer Sport.

Bale, P., Bradbury, D., \& Colley, E. (1986). Anthropometric and Training Variables Related to $10 \mathrm{~km}$ Running Performance. Journal of Sports Medicine, 20, 170-173.

Carter, L. J. E. (Ed.) (2002). The Heath-Carter Anthropometric Somatotype (2nd ed.). San Diego, CA.

Carter, L. J. E., \& Heath, B. H. (1990). Somatotyping-Development and Applications. Press Syndicate of the University of Cambridge (Vol. 5). New York. 
Chovanová, E. (1979). Physique of Top Ice-Hockey Players and Skiers and Its Relation to Their Specialization. Collegium Anthropologicum, 3, 189-193.

Cressie, N. A. C., Withers, R. T., \& Craig, N. P. (1986). The Statistical Analysis of Somatotype Data. American Journal of Physical Anthropology, 29, 197-208. https://doi.org/10.1002/ajpa.1330290509

Durnin, J. V. G. A., \& Womersley, J. (1974). Body Fat Assessed from Total Body Density and Its Estimation from Skinfold Thickness: Measurements on 481 Men and Women Aged from 16 to 72 Years. British Journal of Nutrition, 32, 77-97. https://doi.org/10.1079/BJN19740060

Evans, J. D. (1995). Straightforward Statistics for the Behavioral Sciences. California: Brooks/Cole Publishing Company.

Federolf, P. A. (2012). Quantifying Instantaneous Performance in Alpine Ski Racing. Journal of Sports Sciences, 30, 1063-1068. https://doi.org/10.1080/02640414.2012.690073

FIS (2009). Fédération International de Ski Point List. https://data.fis-ski.com/alpine-skiing/fis-points-lists.html

Gilgien, M., Crivelli, P., Spörri, J., Kröll, J., \& Müller, E. (2015). Characterization of Course and Terrain and Their Effect on Skier Speed in World Cup Alpine Ski Racing. PLoS ONE, 10, e0118119. https://doi.org/10.1371/journal.pone.0118119

Gilgien, M., Spörri, J., Chardonnens, J., Kröll, J., \& Erich, M. (2013). Determination of External Forces in Alpine Skiing Using a Differential Global Navigation Satellite System. Sensors, 13, 9821-9835. https://doi.org/10.3390/s130809821

Gilgien, M., Spörri, J., Kröll, J., Crivelli, P., \& Müller, E. (2014). Mechanics of Turning and Jumping and Skier Speed Are Associated with Injury Risk in Men's World Cup Alpine Skiing: A Comparison between the Competition Disciplines. British Journal of Sports Medicine, 48, 742-747. https://doi.org/10.1136/bjsports-2013-092994

Hébert-Losier, K., Supej, M., \& Holmberg, H.-C. (2014). Biomechanical Factors Influencing the Performance of Elite Alpine Ski Racers. Sports Medicine, 44, 519-533. https://doi.org/10.1007/s40279-013-0132-z

Kenny, L., Wilmore, J., \& Costill, D. (2012). Physiology of Sport and Exercise (5th Edition). Courier Companies, Inc.

Marfell-Jones, M., Olds, T., Stewart, A., \& Carter, L. (2006). International Standards for Anthropometric Assessment (2001st ed.). The International Society for the Advancement of Kinanthropometry.

May, J. R., Veach, T. L., Reed, M. W., \& Griffey, M. S. (1985). A Psychological Study of Health, Injury, and Performance in Athletes on the US Alpine Ski Team. Physician and Sports Medicine, 13, 111-115. https://doi.org/10.1080/00913847.1985.11708905

Nakazato, K., Scheiber, P., \& Müller, E. (2011). A Comparison of Ground Reaction Forces Determined by Portable Force-Plate and Pressure-Insole Systems in Alpine Skiing. Journal of Sports Science and Medicine, 10, 754-762.

Neumayr, G., Koller, A., \& Eibl, G. (2003). Physical and Physiological Factors Associated with Success in Professional Alpine Skiing. International Journal of Sports Medicine, 24, 571-575.

Orvanová, E. (1987). Physical Structure of Winter Sports Athletes. Journal of Sports Sciences, 5, 197-248. https://doi.org/10.1080/02640418708729779

Osgnach, C., Colombo, M., Bosio, A., Freschi, M., Buselli, P., \& Roi, G. (2005). Physical Profile of Top Level Alpine Skiers: Anthropometrical Differences between Italian National Teams Competing in 1982, 1999 and 2005 World Cup. XV International Congress on Sports Rehabilitation and Traumatology, 2-3. 
Reilly, T., Secher, N., Snell, P., \& Williams, C. (1990). Physiology of Sports. E \& FN Spon.

Ropret, R. (2015). Limiting Factors for Success in Alpine Skiing. Physical Education and Sport, 13, 167-176.

Scherr, J., Geissler, U., Waibel, K. H., Blume, K., Maier, W., Halle, M., \& Wolfarth, B. (2011). Physiologische Einflussfaktoren im Alpinen Skirennlauf. Sport-OrthopädieSport-Traumatologie, 27, 239-246. https://doi.org/10.1016/j.orthtr.2011.10.004

Song, T. M. K. (1982). Relationship of Physiological Characteristics to Skiing Performance. The Physician and Sports Medicine, 10, 98-102.

Supej, M. (2010). 3D Measurements of Alpine Skiing with an Inertial Sensor Motion Capture Suit and GNSS RTK System. Journal of Sports Sciences, 28, 759-769. https://doi.org/10.1080/02640411003716934

Supej, M., Kipp, R., \& Holmberg, H. C. (2011). Mechanical Parameters as Predictors of Performance in Alpine World Cup Slalom Racing. Scandinavian Journal of Medicine and Science in Sports, 21, e72-e81. https://doi.org/10.1111/j.1600-0838.2010.01159.x

Taeymans, J., Aerenhouts, D., Clijsen, R., Fässler, R., Clarys, P., \& Baeyens, J. P. (2010). Somatotype and Kinanthropometric Characteristics of Male and Female Junior and Elite Senior Alpine Skiers. In E. Müller, S. Lindinger, \& T. Stöggl (Eds.), 5th International Congress on Science and Skiing (Austria) (pp. 452-460). Meyer \& Meyer Sport.

Turnbull, J. R., Kilding, A. E., \& Keogh, J. W. L. (2009). Physiology of Alpine Skiing. Scandinavian Journal of Medicine and Science in Sports, 19, 146-155.

https://doi.org/10.1111/j.1600-0838.2009.00901.x

Vaverka, F., Vodickova, S., \& Elfmark, M. (2012). Kinetic Analysis of Ski Turns Based on Measured Ground Reaction Forces. Journal of Applied Biomechanics, 28, 41-47. https://doi.org/10.1123/jab.28.1.41

White, A. T., \& Johnson, S. C. (1991). Physciological Comparison of International National and Regional Alpine Skiers. International Journal of Sports Medicine, 12, 374-378.

Wilber, R. L., \& Pitsiladis, Y. P. (2012). Kenyan and Ethiopian Distance Runners: What Makes Them So Good? International Journal of Sport Physiology and Performance, 7, 92-102. https://doi.org/10.1123/ijspp.7.2.92

\section{Submit or recommend next manuscript to SCIRP and we will provide best service for you:}

Accepting pre-submission inquiries through Email, Facebook, LinkedIn, Twitter, etc. A wide selection of journals (inclusive of 9 subjects, more than 200 journals)

Providing 24-hour high-quality service

User-friendly online submission system

Fair and swift peer-review system

Efficient typesetting and proofreading procedure

Display of the result of downloads and visits, as well as the number of cited articles

Maximum dissemination of your research work

Submit your manuscript at: http://papersubmission.scirp.org/

Or contact aa@scirp.org 